\title{
The Topological Distribution of the Chromocenter in Panstrongylus megistus (Burmeister) Malpighian Tubule Cells Examined by Confocal Microscopy
}

\author{
Carlos Henrique L. Imperador ${ }^{1}$, Vera L. C. C. Rodrigues ${ }^{2}$ and Maria Luiza S. Mello ${ }^{1 *}$ \\ ${ }^{1}$ Department of Structural and Functional Biology, Institute of Biology, University of Campinas (Unicamp), \\ 13083-862 Campinas, SP, Brazil \\ ${ }^{2}$ Superintendence for Control of Endemic Diseases (SUCEN), 13840-000 Mogi-Guaçu, SP, Brazil
}

Received November 1, 2020; accepted November 25, 2020

\begin{abstract}
Summary Panstrongylus megistus (Burmeister) and Triatoma infestans (Klug), blood-sucking hemipterans in the Reduviidae family, are vectors of Chagas disease. Both species exhibit holocentric chromosomes and conspicuous heterochromatin bodies (chromocenters), but they differ in chromosome number and chromocenter structure and composition patterns. In the Malpighian tubule cells of T. infestans, the chromocenters are positioned close to the nuclear periphery throughout the life of the insect, with no apparent association with overall gene silencing. Because chromocenter topology may vary in different species of the same genus and the spatial distribution pattern of the chromocenter of $P$. megistus has not yet been described, we used confocal microscopy to evaluate the spatial organization of this heterochromatic body in the Malpighian tubule cells of this species during nymphal development and in the adult phase compared to data reported for T. infestans. Despite the differences in chromocenter composition, structural pattern, and size between P. megistus and T. infestans, the chromocenter of $P$. megistus nymphs and adults, similar to those of $T$. infestans, was found to occupy a nonincidental position close to the nuclear periphery. The topological pattern observed at the chromocenter of $P$. megistus, which is consistent with the previous report of highly concentrated dimethylated histone H3 lysine 9 residues at the nuclear periphery was not found to be directly related to gene silencing or modulation.
\end{abstract}

Keywords Heterochromatin, Spatial distribution, Hemipteran, Fluorescent Feulgen reaction.

Panstrongylus megistus (Burmeister, 1835) and Triatoma infestans (Klug, 1834) are blood-sucking insects in the Reduviidae hemipteran family that serve as important vectors of Chagas disease. P. megistus, which is native to Brazil, is particularly relevant for the spread of this disease because it has become associated with human habitations after the extensive destruction of its natural habitats (Silveira 2000).

Both P. megistus and T. infestans exhibit holokinetic (holocentric) chromosomes and constitutive heterochromatin bodies, known as chromocenters, containing AT-rich DNA (Ueshima 1966, Mello 1971, 1975, Mello et al. 1986, Alvarenga et al. 2011, 2012). In contrast, these species differ in the number of chromosomes and in chromocenter structure. While $P$. megistus contains nine autosomal pairs and multiple sex chromosomes $\left(\mathrm{X}_{1} \mathrm{X}_{2} \mathrm{Y}\right.$ in males and $\mathrm{X}_{1} \mathrm{X}_{1} \mathrm{X}_{2} \mathrm{X}_{2}$ in females), T. infestans contains 10 autosomal pairs and $\mathrm{XY} / \mathrm{XX}$ sex chromosomes (Ueshima 1966). While in T. infestans, the chromocenters are large, conspicuous structures (Mello 1971, 1979) encapsulating at least three pairs of autosomes and the sex chromosomes in T. infestans (Sch-

\footnotetext{
*Corresponding author, e-mail: mlsmello@unicamp.br DOI: $10.1508 /$ cytologia. 86.47
}

reiber et al. 1972, Solari 1979), in P. megistus, a single small chromocenter is detected only in male specimens and has been assumed to consist of the $\mathrm{Y}$ chromosome in somatic cells (Mello et al. 1986) and of the Y chromosome plus the associated $\mathrm{X}_{1}$ and $\mathrm{X}_{2}$ chromosomes in meiotic cells at the "diffuse stage" (Crossa et al. 2002). In contrast to T. infestans, no diversification of the chromocenter morphological pattern occurs in the Malpighian tubules of P. megistus (Mello 1975, Mello et al. 1986). Regarding the presence of histone epigenetic markers, while acetylated H3K9, H4K8, and H4K16 and mono(H3K9me) and dimethylated $\mathrm{H} 3 \mathrm{~K} 9$ (H3K9me2) are absent in the Malpighian tubule chromocenters of both species, H3K9me2 markers are predominantly distributed at the nuclear periphery only in P. megistus (Alvarenga et al. 2016, 2018).

Chromatin organization and distribution in subdomains is relevant to nuclear physiology (Fritz et al. 2016, Jagannathan et al. 2019). The spatial distribution of heterochromatin in interphase, either as isolated loci or clustered together into conspicuous chromatin bodies known as chromocenters, has been associated with proximity to the nuclear periphery in several organisms. In certain cases, the nonincidental localization of chromocenters has been associated with a high content of 
gene-poor chromosome domains or gene silencing; in contrast, euchromatin is mostly positioned in the nuclear center and is rich in transcriptionally active genes (Croft et al. 1999, Bártova et al. 2008, Politz et al. 2013, Wijchers et al. 2015).

In the Malpighian tubules of $T$. infestans, the chromocenters are distributed relatively close to the nuclear edge but they are not endowed with overall gene silencing, because their boundaries contain 18S rDNA sites even in regions facing the nuclear periphery (Imperador et al. 2020). However, because the spatial distribution of chromocenters within the cell nucleus may vary between different species of the same genus (Ellison and Howard 1981, Hochstrasser et al. 1986), the data reported for $T$. infestans may not be extrapolated to other chromocentercontaining reduviid hemipterans, including P. megistus. Considering that the number of chromosomes and the size and chromosome content of the chromocenter of $P$. megistus differ from those of $T$. infestans and that there is an absence of data regarding the topological distribution of the chromocenter in the Malpighian tubule cell nuclei of $P$. megistus, the spatial distribution of the chromocenter in this species was investigated using confocal microscopy and was compared throughout insect development with data reported for T. infestans (Imperador et al. 2020).

Materials and methods

\section{Insects}

Male third- and fifth-instar nymphs and adults of a domestic population of $P$. megistus originating from natural populations of insects collected in the eastern region of the state of São Paulo were supplied by the insect facility of the Superintendence for Control of Endemic Diseases of the state of São Paulo (SUCEN) at Mogi-Guaçu (Brazil). In the SUCEN facility, the $P$. megistus specimens were reared at $28^{\circ} \mathrm{C}$ and $80 \%$ relative humidity and fed on hen's blood once per week following the animal care and ethical procedures registered at the National Council of Animal Experimentation Control (COBEA) from the Brazilian Ministry of Science, Technology and Innovation (accreditation protocol no. 01200.003280/2014-28). Three to five specimens of each developmental stage were used. The SUCEN Scientific and Ethics Committee approved this investigation (Protocol no. 64405/2015).

\section{Fixation and cytochemistry}

Whole-mounted Malpighian tubules were used because of their well-known cell biology, cytogenetics, fine structure, physiology, and chromatin epigenetics (Mello 1975, Dolder and Mello 1979, Wigglesworth 1984, Mello et al. 1986, Alvarenga et al. 2012, 2018). These organs were fixed in a mixture of absolute ethanol and glacial acetic acid $(3: 1, \mathrm{v} / \mathrm{v})$ for $1 \mathrm{~min}$, rinsed in $70 \%$ ethanol for $5 \mathrm{~min}$, and then either subjected to an ordinary Feulgen reaction, to obtain a global DNA cytochemical response or subjected to the fluorescent Feulgen reaction, which is required for DNA/chromatin localization using confocal microscopy (Mello and Vidal 2017). In both cases, DNA depurination by acid hydrolysis was performed in $4 \mathrm{M} \mathrm{HCl}$ for $65 \mathrm{~min}$ at $25^{\circ} \mathrm{C}$. For the fluorescent Feulgen staining, the Schiff reagent was diluted in sulfurous water $(1: 9, \mathrm{v} / \mathrm{v})$ (Imperador et al. 2020). Following treatment with the Schiff reagent, the preparations were rinsed in three baths of sulfurous water ( $5 \mathrm{~min}$ each) and then in distilled water, air-dried, cleared in xylene for $10 \mathrm{~min}$, and mounted in Canada balsam (ordinary Feulgen reaction) or VECTASHIELD (Vector Laboratories) (fluorescent Feulgen reaction).

\section{Ordinary light microscopy}

The preparations subjected to nonfluorescent Feulgen staining were examined using a Zeiss Axiophot 2 microscope (Carl Zeiss) equipped with a Neofluar $40 \times / 0.75$ objective, optovar factor 2 , and a 0.90 condenser, and images of the nuclei were captured using an AxioCam HRc color video camera.

\section{Confocal microscopy}

The fluorescent images were examined using a Leica TS SP5 II broadband confocal microscope (Leica Microsystems) equipped with argonium and $543 \mathrm{~nm}$ and $633 \mathrm{~nm}$ helium-neon lasers, $63 \times$ and $100 \times$ objectives, and the Leica Application Suite AF software (Leica Microsystems) at the LaCTAD facilities (Unicamp, Campinas, Brazil). A spacing of $0.13 \mu \mathrm{m}$ between optical sections was used for each nucleus. Because the nuclear size varies as a function of the insect developmental phase as polyploidization progresses (Mello 1975), the software provided further spacing compensation during $3 \mathrm{D}$ reconstruction. A total of 29 nuclei from third-instar nymphs, 26 nuclei from fifth-instar nymphs, and $15 \mathrm{nu}-$ clei from adults were analyzed.

\section{Image analysis and statistics}

The axial distances between the chromocenters and the nuclear periphery were measured in the $\mathrm{X}, \mathrm{Y}$, and $\mathrm{Z}$ axes using the Image-Pro Plus 7 software (Media Cybernetics, Inc., Rockville, MD, USA). The representation of the optical sections according to these axes followed the same schema previously reported for $T$. infestans (Imperador et al. 2020). For comparisons that required Kruskal-Wallis and Mann-Whitney tests, the Minitab18 software (State College, PA, USA) was used.

\section{Results}

The nuclei and chromocenter in the Feulgen-stained Malpighian tubule cells of $P$. megistus male nymphs and adults are ellipsoidal. The chromocenter stains deeply 

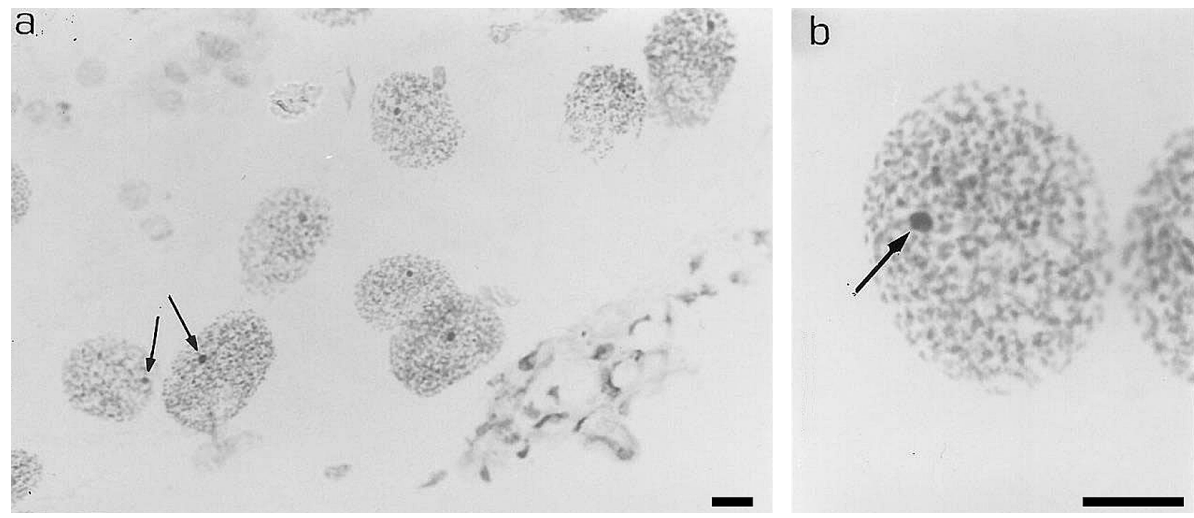

Fig. 1. Feulgen-stained Malpighian tubule cell nuclei of a fifth-instar male nymph of P. megistus (a, b). The arrows indicate the chromocenter. Scale bars $=10 \mu \mathrm{m}$.

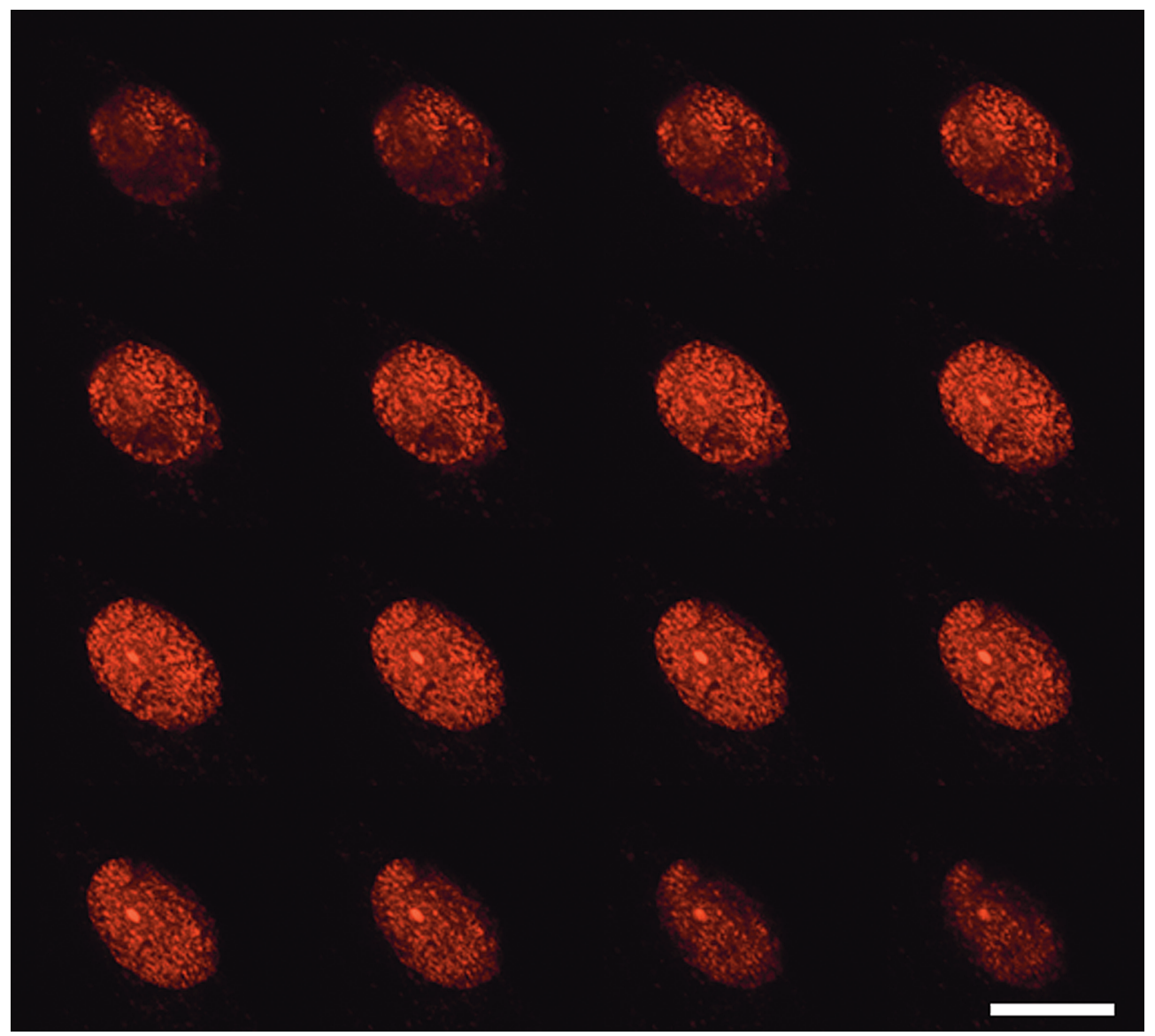

Fig. 2. Image gallery composed of a sequence of optical sections obtained using confocal microscopy of a fluorescent Feulgenstained Malpighian tubule cell nucleus of a fifth-instar nymph of $P$. megistus. A spacing of $0.13 \mu \mathrm{m}$ between optical sections was used. Scale bar $=20 \mu \mathrm{m}$.

in the ordinary Feulgen reaction (Fig. 1) and exhibits a more intense response to the fluorescent Feulgen reaction than the rest of the chromatin (euchromatin) (Fig. 2). An example of a sequence of optically sectioned images captured with confocal microscopy from a fifth-instar Malpighian tubule cell nucleus stained with the fluorescent Feulgen reaction is presented in Fig. 2.

The measurement of the nuclear diameters and the distances between the chromocenter surface and the nuclear periphery in the opposite directions (distal long and proximal short distances) revealed differences in all coordinates (Fig. 3, Tables 1 and 2). These differences indicate that the chromocenter is not centrally positioned in the cell nuclei of P. megistus and that there is relative proximity between the chromocenter and the nuclear periphery in all studied phases (Table 2). Despite the proximity of the chromocenter to the nuclear periphery, the proximal and distal distances between the chromocenters and the nuclear periphery in the X-, Y- and Zaxes demonstrated increased variability (Table 1). The 
a

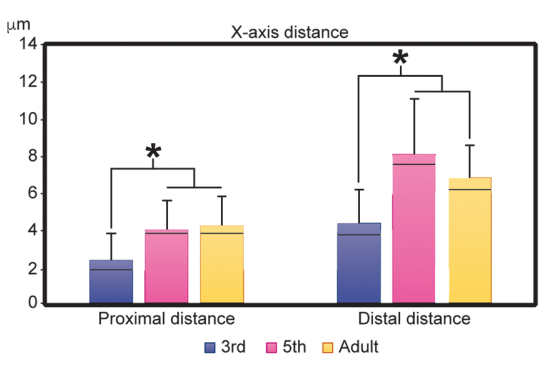

b

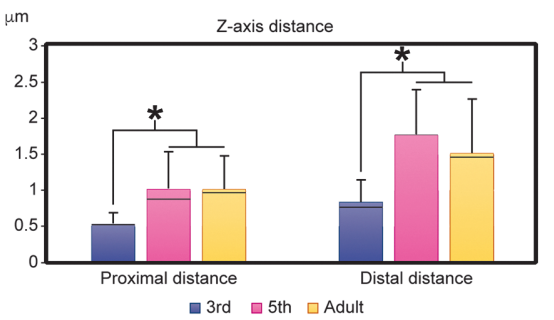

C

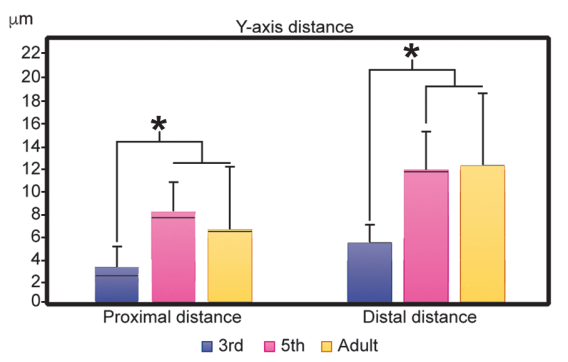

d

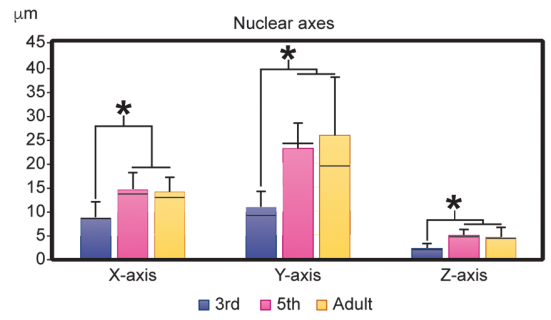

Fig. 3. Comparison of the distances in the $\mathrm{X}, \mathrm{Y}$, and $\mathrm{Z}$ axes between the chromocenter and the nuclear periphery in the fluorescent Feulgen-stained cell nuclei of Malpighian tubules of P. megistus (a-c). The nuclear diameters (axes) are also compared (d). The vertical lines on the bars indicate the mean standard deviations; the horizontal lines in the bars indicate the median values. *Differences significant at $P_{0.05}$ between the compared groups. $n=29$ (3rd-instar nymphs), 26 (5th-instar nymphs) and 15 (adults). The statistical comparisons are listed in Tables 2 and 3.

Table 1. Proximal and distal distances between the chromocenter and the nuclear periphery in Malpighian tubule cells of $P$. megistus.

\begin{tabular}{|c|c|c|c|c|c|c|c|c|c|c|}
\hline \multirow{2}{*}{ Distances $(\mu \mathrm{m})$} & \multirow{2}{*}{ Axes } & \multicolumn{3}{|c|}{ Third instar nymphs $(n=29)$} & \multicolumn{3}{|c|}{ Fifth instar nymphs $(n=26)$} & \multicolumn{3}{|c|}{ Adults $(n=15)$} \\
\hline & & $\mathrm{X}$ & SD & $\mathrm{CV}(\%)$ & $\mathrm{X}$ & SD & $\mathrm{CV}(\%)$ & $\mathrm{X}$ & SD & $\mathrm{CV}(\%)$ \\
\hline \multirow[t]{3}{*}{ Proximal } & $\mathrm{X}$ & 2.43 & 1.44 & 59.32 & 4.11 & 1.54 & 37.50 & 4.42 & 1.50 & 34.02 \\
\hline & $\mathrm{Y}$ & 3.50 & 1.83 & 52.34 & 8.24 & 2.54 & 30.82 & 8.94 & 5.64 & 63.10 \\
\hline & $\mathrm{Z}$ & 0.53 & 0.15 & 29.85 & 1.00 & 0.54 & 54.11 & 1.01 & 0.46 & 45.97 \\
\hline \multirow[t]{3}{*}{ Distal } & $\mathrm{X}$ & 4.40 & 1.84 & 41.77 & 8.13 & 3.12 & 38.39 & 6.96 & 1.64 & 23.64 \\
\hline & $\mathrm{Y}$ & 5.63 & 1.55 & 27.53 & 11.82 & 3.58 & 30.32 & 14.59 & 6.34 & 43.48 \\
\hline & $\mathrm{Z}$ & 0.86 & 0.26 & 31.28 & 1.78 & 0.63 & 35.16 & 1.53 & 0.73 & 47.82 \\
\hline \multirow[t]{3}{*}{ Nuclear diameter } & $\mathrm{X}$ & 8.68 & 3.12 & 35.95 & 14.41 & 3.87 & 26.80 & 14.21 & 2.90 & 20.16 \\
\hline & $\mathrm{Y}$ & 11.18 & 3.04 & 27.24 & 23.14 & 5.68 & 24.54 & 25.90 & 12.23 & 47.23 \\
\hline & Z & 2.60 & 0.59 & 22.80 & 4.85 & 1.33 & 27.59 & 4.52 & 2.05 & 45.23 \\
\hline
\end{tabular}

$\mathrm{CV}$, coefficient of variability; SD, standard deviation; $\mathrm{X}$, arithmetic means

nuclear diameters and the distal and proximal distances between the chromocenter and the nuclear periphery in the X-, Y- and Z-coordinates were observed to increase throughout nymphal development, which is when polyploidization occurs in the Malpighian tubules, and were found to arrest in the adult phase, which is when polyploidization ceases (Mello 1975) (Table 3).

\section{Discussion}

The structural results obtained for $P$. megistus in the present study showed similarities with those previously reported for T. infestans (Imperador et al. 2020), despite their previously described differences in chromocenter composition, structural pattern, and size (Schreiber et al. 1972, Mello 1975, Solari 1979, Mello et al. 1986, Crossa et al. 2002). Because the Feulgen reaction is a reliable cytochemical test to reveal and quantify DNA (Mello and Vidal 2017), the pattern of chromocenter distribution within the cell nuclei of $P$. megistus could be adequately assessed using confocal microscopy.

The function of the chromocenter and the reason for its close proximity to the nuclear periphery in the cells of $P$. megistus are questions that have also been raised regarding the constitutive heterochromatin of many other organisms and are considered not yet fully addressed (Allshire and Madhani 2018).

Heterochromatin self-association, such as that occurring in chromocenters, and satellite DNA repeats have been considered a driving force in the formation and maintenance of the 3D structure of the nucleus (Wijchers et al. 2015, Jagannathan et al. 2018, 2019, Ostromyshenskii et al. 2018). Chromocenters formed from bundling pericentromeric satellite DNA have been considered to play the role of packaging the genome within a single nucleus through the formation of a modu- 
Table 2. Proximal and distal distances between the chromocenter (s) and the nuclear periphery in Feulgen-stained cell nuclei of Malpighian tubules of $P$. megistus compared in the $\mathrm{X}$-, Y- and Z-optical axes.

\begin{tabular}{|c|c|c|c|c|c|}
\hline Developmental stage & Parameters & Axis comparison & Test & $\mathrm{P}$ & Decision \\
\hline \multirow[t]{12}{*}{ Nymphal 3rd instar } & \multirow[t]{4}{*}{ Proximal distance } & $\mathrm{X} v s . \mathrm{Y} v s . \mathrm{Z}$ & KW & 0.0010 & SS \\
\hline & & $\mathrm{X} v s . \mathrm{Y}$ & MW & 0.0349 & $\mathrm{~S}$ \\
\hline & & $\mathrm{X} v s . \mathrm{Z}$ & MW & 0.0000 & SS \\
\hline & & Y vs. Z & MW & 0.0000 & SS \\
\hline & \multirow[t]{4}{*}{ Distal distance } & $\mathrm{X} v s . \mathrm{Y} v s . \mathrm{Z}$ & KW & 0.0000 & SS \\
\hline & & $\mathrm{X} v s . \mathrm{Y}$ & MW & 0.0250 & $\mathrm{~S}$ \\
\hline & & $\mathrm{X} v$ s. $\mathrm{Z}$ & MW & 0.0000 & SS \\
\hline & & Y vs. Z & MW & 0.0000 & SS \\
\hline & \multirow[t]{4}{*}{ Nucleus axis } & $\mathrm{X} v s . \mathrm{Y} v s . \mathrm{Z}$ & KW & 0.0000 & SS \\
\hline & & $\mathrm{X} v s . \mathrm{Y}$ & MW & 0.0166 & $\mathrm{~S}$ \\
\hline & & $\mathrm{X} v s . \mathrm{Z}$ & MW & 0.0000 & SS \\
\hline & & $\mathrm{Y} v s . \mathrm{Z}$ & MW & 0.0000 & SS \\
\hline \multirow[t]{12}{*}{ Nymphal 5th instar } & \multirow[t]{4}{*}{ Proximal distance } & $\mathrm{X} v s . \mathrm{Y} v s . \mathrm{Z}$ & KW & 0.0000 & SS \\
\hline & & $\mathrm{X} v s . \mathrm{Y}$ & MW & 0.0000 & SS \\
\hline & & $\mathrm{X} v$ s. $\mathrm{Z}$ & MW & 0.0000 & SS \\
\hline & & Y vs. Z & MW & 0.0000 & SS \\
\hline & \multirow[t]{4}{*}{ Distal distance } & $\mathrm{X} v s . \mathrm{Y} v s . \mathrm{Z}$ & KW & 0.0000 & SS \\
\hline & & $\mathrm{X} v s . \mathrm{Y}$ & MW & 0.0005 & SS \\
\hline & & $\mathrm{X} v$ s. $\mathrm{Z}$ & MW & 0.0000 & SS \\
\hline & & Y vs. Z & MW & 0.0000 & SS \\
\hline & \multirow[t]{4}{*}{ Nucleus axis } & $\mathrm{X} v s . \mathrm{Y} v s . \mathrm{Z}$ & KW & 0.0000 & SS \\
\hline & & $\mathrm{X} v s . \mathrm{Y}$ & MW & 0.0000 & SS \\
\hline & & $\mathrm{X} v s . \mathrm{Z}$ & MW & 0.0000 & SS \\
\hline & & $\mathrm{Y} v s . \mathrm{Z}$ & MW & 0.0000 & SS \\
\hline \multirow[t]{12}{*}{ Adult } & \multirow[t]{4}{*}{ Proximal distance } & $\mathrm{X} v s . \mathrm{Y} v s . \mathrm{Z}$ & KW & 0.0000 & SS \\
\hline & & $\mathrm{X} v s . \mathrm{Y}$ & MW & 0.0000 & SS \\
\hline & & $\mathrm{X} v s . \mathrm{Z}$ & MW & 0.0000 & SS \\
\hline & & Y vs. Z & MW & 0.0000 & SS \\
\hline & \multirow[t]{4}{*}{ Distal distance } & $\mathrm{X} v s . \mathrm{Y} v s . \mathrm{Z}$ & KW & 0.0000 & SS \\
\hline & & $\mathrm{X} v s . \mathrm{Y}$ & MW & 0.0000 & SS \\
\hline & & $\mathrm{X} v s . \mathrm{Z}$ & MW & 0.0000 & SS \\
\hline & & Y vs. Z & MW & 0.0000 & SS \\
\hline & \multirow[t]{4}{*}{ Nucleus axis } & $\mathrm{X} v s . \mathrm{Y} v s . \mathrm{Z}$ & KW & 0.0000 & SS \\
\hline & & $\mathrm{X} v s . \mathrm{Y}$ & MW & 0.0000 & SS \\
\hline & & $\mathrm{X} v s . \mathrm{Z}$ & MW & 0.0000 & SS \\
\hline & & Y vs. Z & MW & 0.0000 & SS \\
\hline
\end{tabular}

KS, Kruskal-Wallis; MW, Mann-Whitney; NS, non-significant; S, significant; SS, highly significant; vs, versus.

lar network that results from associations between two sequence-specific satellite DNA-binding proteins bound to their cognate satellite DNAs (Jagannathan et al. 2018, 2019). Although a detailed examination of some of the published images of $T$. infestans somatic cell nuclei suggests the connection to their chromocenters of several chromosomes that do not belong to these heterochromatin bodies (Fig. 1a in Mello 1997; Figs. 2-4 in Mello 1979), no such evidence has been observed in P. megistus male somatic cells.

The nonincidental distribution of the chromocenter in the cell nuclei of $P$. megistus Malpighian tubules was consistent with observations in other animal species, including T. infestans (Imperador et al. 2020). In Drosophila melanogaster, the distribution of pericentromeric heterochromatin in specific nuclear spaces is assumed to be functionally related to the organization of the nucleolus (Wasserlauf et al. 2020). This event may also occur in P. megistus Malpighian tubules because a confocal-fluorescence in situ hybridization study has revealed that both the peripheral and inner regions of the chromocenter contain 18S rDNA (Alvarenga et al. 2018), although 18S rDNA signals are also detected outside the chromocenter (Alvarenga et al. 2018), likely due to ribosomal genes present in one autosomal chromosome pair (Panzera et al. 2012).

Although there is no consensus on whether the topological organization of a chromocenter is associated with gene-poor chromosome domains and/or silenced chromatin, there are reports indicating that the nuclear periphery is not refractory to gene transcription and that it can contain concentrated histone epigenetic marks that participate in the modulation of certain genes and silencing factors (Ruault et al. 2008, Towbin et al. 2009, 2013, Meister and Taddei 2013). A deep concentration of $\mathrm{H} 3 \mathrm{~K} 9 \mathrm{me} 2$ residues has been demonstrated at the nuclear periphery in the Malpighian tubule cells of P. megistus (Alvarenga et al. 2018). In other organisms, this epigenetic mark has been associated with the creation of a platform for the binding of the heterochromatin structural 
Table 3. Statistical comparisons for X-, Y-, and Z-axes distance of chromocenters and nuclear axes of Feulgen-stained nuclei of Malpighian tubule cells of $P$. megistus.

\begin{tabular}{|c|c|c|c|c|}
\hline Parameters & Stage comparison & Test & $\mathrm{P}$ & Decision \\
\hline \multirow[t]{4}{*}{$\mathrm{X}$-axis proximal distance } & Third- $v s$. fifth-instar nymphs $v s$. adults & KW & 0.0000 & SS \\
\hline & Third- vs. fifth-instar nymphs & MW & 0.0003 & SS \\
\hline & Third-instar nymphs $v s$. adults & MW & 0.0004 & SS \\
\hline & Fifth-instar nymphs $v s$. adults & MW & 0.8430 & NS \\
\hline \multirow[t]{4}{*}{$\mathrm{X}$-axis distal distance } & Third- vs. fifth-instar nymphs $v s$. adults & KW & 0.0000 & SS \\
\hline & Third- vs. fifth-instar nymphs & MW & 0.0000 & SS \\
\hline & Third-instar nymphs $v s$. adults & MW & 0.0004 & SS \\
\hline & Fifth-instar nymphs vs. adults & MW & 0.2157 & NS \\
\hline \multirow[t]{4}{*}{ Y-axis proximal distance } & Third- $v s$. fifth-instar nymphs $v s$. adults & KW & 0.0000 & SS \\
\hline & Third- vs. fifth-instar nymphs & MW & 0.0000 & SS \\
\hline & Third-instar nymphs vs. adults & MW & 0.0002 & SS \\
\hline & Fifth-instar nymphs $v s$. adults & MW & 0.7556 & NS \\
\hline \multirow[t]{4}{*}{ Y-axis distal distance } & Third- $v s$. fifth-instar nymphs $v s$. adults & KW & 0.0000 & SS \\
\hline & Third- vs. fifth-instar nymphs & MW & 0.0000 & SS \\
\hline & Third-instar nymphs vs. adults & MW & 0.0000 & SS \\
\hline & Fifth-instar nymphs vs. adults & MW & 0.3790 & NS \\
\hline \multirow[t]{4}{*}{$\mathrm{Z}$-axis proximal distance } & Third- $v s$. fifth-instar nymphs $v s$. adults & KW & 0.0000 & SS \\
\hline & Third- $v s$. fifth-instar nymphs & MW & 0.0005 & SS \\
\hline & Third-instar nymphs $v s$. adults & MW & 0.0002 & SS \\
\hline & Fifth-instar nymphs $v s$. adults & MW & 0.9892 & NS \\
\hline \multirow[t]{4}{*}{$\mathrm{Z}$-axis distal distance } & Third- vs. fifth-instar nymphs $v s$. adults & KW & 0.0000 & SS \\
\hline & Third- $v s$. fifth-instar nymphs & MW & 0.0000 & SS \\
\hline & Third-instar nymphs $v s$. adults & MW & 0.0012 & SS \\
\hline & Fifth-instar nymphs vs. adults & MW & 0.1848 & NS \\
\hline \multirow[t]{4}{*}{ Nucleus $\mathrm{X}$-axis } & Third- $v s$. fifth-instar nymphs $v s$. adults & KW & 0.0000 & SS \\
\hline & Third- vs. fifth-instar nymphs & MW & 0.0000 & SS \\
\hline & Third-instar nymphs vs. adults & MW & 0.0000 & SS \\
\hline & Fifth-instar nymphs vs. adults & MW & 0.8817 & NS \\
\hline \multirow[t]{4}{*}{ Nucleus Y-axis } & Third- $v s$. fifth-instar nymphs $v s$. adults & KW & 0.0000 & SS \\
\hline & Third- vs. fifth-instar nymphs & MW & 0.0000 & SS \\
\hline & Third-instar nymphs vs. adults & MW & 0.0000 & SS \\
\hline & Fifth-instar nymphs vs. adults & MW & 0.8603 & NS \\
\hline \multirow[t]{4}{*}{ Nucleus Z-axis } & Third- $v s$. fifth-instar nymphs $v s$. adults & KW & 0.0000 & SS \\
\hline & Third- $v s$. fifth-instar nymphs & MW & 0.0000 & SS \\
\hline & Third-instar nymphs vs. adults & MW & 0.0032 & SS \\
\hline & Fifth-instar nymphs vs. adults & MW & 0.5247 & NS \\
\hline
\end{tabular}

KW, Kruskal-Wallis; MW, Mann-Whitney; NS, not significant; S, significant; SS, highly significant; vs, versus.

protein HP1 (Yokochi et al. 2009) and has been claimed to represent "a specific mark of nuclear peripheral heterochromatin that acts as a 3D architectural guidepost" (Poleshko et al. 2019). The maintenance of the spatial positioning of the chromocenter close to the nuclear periphery as polyploidization advances during the nymphal development of $P$. megistus may thus be related to the presence of $\mathrm{H} 3 \mathrm{~K} 9 \mathrm{me} 2$-enriched genomic regions adjacent to this nuclear region (Alvarenga et al. 2018). The variability in the proximal and distal distances between the chromocenter and the nuclear periphery in $P$. megistus as well as in T. infestans, may suggest for both species that although the chromocenters are close to the nuclear periphery, they may exhibit a certain degree of mobility at this nuclear region (Imperador et al. 2020).

Although chromocenters are considered to comprise a repressive environment in the nucleus (Politz et al. 2013), the proximity of this heterochromatic body to the nuclear periphery in $P$. megistus may not be merely associated with global gene silencing. The chromocenter containing several copies of the endoreplicated $\mathrm{Y}$ chromosome in the polyploid cells of the Malpighian tubules of this species may be not totally silent or empty of genes. Although not closely related to P. megistus, the reduviid Rhodnius prolixus contains nine genes in its $\mathrm{Y}$ chromosome, one with gut-restricted expression (Koerich et al. 2016).

In conclusion, the chromocenter of $P$. megistus shows a peripheral distribution pattern in the Malpighian tubule cell nuclei in which it may exhibit dynamic mobility, similar to the spatial organization of the single- and multi-chromocentered nuclei in the Malpighian tubules of $T$. infestans despite their differences in composition, structural organization, and size. The function of the $P$. megistus chromocenter in the context of the general nuclear organization in a somatic cell and the reason for its specific positioning close to the nuclear periphery, are questions that warrant further investigation. Molecular 
biology studies, especially concerning genomic sequencing, types of repetitive DNA-cognate proteins, and immunocytochemical assays in conjunction with confocal microscopy and other advanced microscopies, may help to elucidate the nature of this chromocenter.

\section{Acknowledgements}

Carlos Henrique de Lima Imperador received a fellowship from the Coordenação de Aperfeiçoamento de Pessoal de Nível Superior (CAPES, Brazil-Finance code 001). Maria Luiza Silveira Mello received a fellowship from CNPq (grant no. 304668/2014-1). This research was supported by the São Paulo state Research Foundation (FAPESP, Brazil; grant no. 2015/10356-2) and the Brazilian National Council for Research and Development (CNPq, grant no. 304668/2014-1). The funders had no role in the study design, data collection and analysis, decision to publish, or preparation of the manuscript.

\section{References}

Allshire, R. C. and Madhani, H. D. 2018. Ten principles of heterochromatin formation and function. Nat. Rev. Mol. Cell Biol. 19: 229-244.

Alvarenga, E. M., Mondin, M., Martins, J. A., Rodrigues, V. L. C. C., Vidal, B. C., Rincones, J., Carazzolle, M. F., Andrade, L. M. and Mello, M. L. S. 2011. Spatial distribution of AT- and GC-rich DNA within interphase cell nuclei of Triatoma infestans Klug. Micron 42: 568-578.

Alvarenga, E. M., Imperador, C. H. L., Bardella, V. B., Rodrigues, V. L. C. C., Mondin, M., Cabral-de-Mello, D. C., Moraes, A. S. and Mello, M. L. S. 2018. Histone acetylation and methylation marks in chromatin of Panstrongylus megistus (Hemiptera, Reduviidae). Acta Histochem. 120: 572-577.

Alvarenga, E. M., Mondin, M., Rodrigues, V. L. C. C., Andrade, L. M., Vidal, B. C. and Mello, M. L. S. 2012. Contribution of AT-, GC-, and methylated cytidine-rich DNA to chromatin composition in Malpighian tubule cell nuclei of Panstrongylus megistus (Hemiptera, Reduviidae). Acta Histochem. 114: 665-672.

Alvarenga, E. M., Rodrigues, V. L. C. C., Moraes, A. S., Naves, L. S., Mondin, M., Felisbino, M. B. and Mello, M. L. S. 2016. Histone epigenetic marks in heterochromatin and euchromatin of the Chagas disease vector, Triatoma infestans. Acta Histochem. 118: 401-412.

Bártova, E., Krejci, J., Harnicarová, A., Galiová, G. and Kozubek, S. 2008. Histone modifications and nuclear architecture: A review. J. Histochem. Cytochem. 56: 711-721.

Croft, J. A., Bridger, J. M., Byole, S., Perry, P., Teagu, P. and Bickmore, W. A. 1999. Differences in the localization and morphology of chromosomes in the human nucleus. J. Cell Biol. 145: 1119-1131.

Crossa, R. P., Hernandez, M., Caraccio, M. N., Rose, V., Valente, S. A. S., Valente, V. C., Mejia, J. M., Angulo, V. M., Ramirez, C. M. S., Roldan, J., Vargas, F., Wolff, M. and Panzera, F. 2002. Chromosomal evolution trends of the genus Panstrongylus (Hemiptera, Reduviidae), vectors of Chagas disease. Infect. Genet. Evol. 2: 47-56.

Dolder, H. and Mello, M. L. S. 1979. Ultrastructure of the Malpighian tube cells of Panstrongylus megistus (Burmeister). J. Submicrosc. Cytol. 11: 385-394.

Ellison, J. R. and Howard, G. C. 1981. Non-random position of the
AT-rich DNA sequences in early embryos of Drosophila virilis. Chromosoma 83: 555-561.

Fritz, A., Barutcu, A. R., Martin-Buley, L., Van Wijnen, A. J., Zaidi, S. K., Imbalzano, A. N., Lian, J. B., Stein, J. L. and Stein, G. S. 2016. Chromosomes at work: Organization of chromosome territories in the interphase nucleus. J. Cell. Biochem. 117: 9-19.

Hochstrasser, M., Mathog, D., Gruenbaum, Y., Saumweber, H. and Sedat, J. W. 1986. Spatial organization of chromosomes in the salivary gland nuclei of Drosophila melanogaster. J. Cell Biol. 102: $112-123$.

Imperador, C. H. L., Bardella, V. B., dos Anjos, E. H. M., Rodrigues, V. L. C. C., Cabral-de-Mello, D. C. and Mello, M. L. S. 2020. Spatial distribution of heterochromatic bodies in the nuclei of Triatoma infestans (Klug). Microsc. Microanal. 26: 567-574.

Jagannathan, M., Cummings, R. and Yamashita, Y. M. 2018. A conserved function for pericentromeric satellite DNA. eLife 7: e34122.

Jagannathan, M., Cummings, R. and Yamashita, Y. M. 2019. The modular mechanism of chromocenter formation in Drosophila. eLife 8: e43938.

Koerich, L. B., Dupim, E. G., Faria, L. L., Dias, F. A., Dias, A. F., Trindade, G. S., Mesquita, R. D. and Carvalho, A. B. 2016. First report of Y-linked genes in the kissing bug Rhodnius prolixus. BMC Genomics 17: 100.

Meister, P. and Taddei, A. 2013. Building silent compartments at the nuclear periphery. A recurrent theme. Curr. Opin. Genet. Dev. 23: 96-103.

Mello, M. L. S. 1971. Nuclear behavior in the Malpighian tubes of Triatoma infestans. (Reduv., Hemiptera). Cytologia 36: 42-49.

Mello, M. L. S. 1975. Feulgen-DNA values and ploidy degrees in the Malpighian tubes of some triatomids. Rev. Brasil. Pesq. Med. Biol. 8: 101-107.

Mello, M. L. S. 1979. Patterns of lability towards acid hydrolysis in heterochromatin and euchromatin of Triatoma infestans Klug. Cell. Mol. Biol. 24: 1-16.

Mello, M. L. S. 1997. Cytochemistry of DNA, RNA and nuclear proteins. Brazil. J. Genet. 20: 257-264.

Mello, M. L. S., Randi, M. A., Giorgio, S., Ferraz-Filho, A. N., Rodrigues, V. L. C. C., Rocha-e-Silva, E. O. and Cordeiro, J. A. 1986. Number of chromosomes, Feulgen-DNA content and nuclear phenotypes in domestic and wild specimens of Panstrongylus megistus. Ann. Trop. Med. Parasitol. 80: 641-648.

Mello, M. L. S. and Vidal, B. C. 2017. The Feulgen reaction: A brief review and new perspectives. Acta Histochem. 119: 603-609.

Ostromyshenskii, D. I., Chernyaeva, E. N., Kuznetsova, I. S. and Podgornaya, O. I. 2018. Mouse chromocenters DNA content: Sequencing and in silico analysis. BMC Genomics 19: 151.

Panzera, Y., Pita, S., Ferreiro, M. J., Fernandis, I., Lages, C., Pérez, R., Silva, A. E., Guerra, M. and Panzera, F. 2012. High dynamics of rDNA cluster location in kissing bug holocentric chromosomes (Triatominae, Heteroptera). Cytogenet. Genome Res. 138: $56-67$.

Poleshko, A., Smith, C. L., Nguyen, S. C., Sivaramakrishnan, P., Wong, K. G., Murray, J. I., Lakadamyali, M., Joyce, E. F., Jain, R. and Epstein, J. A. 2019. H3K9me2 orchestrates inheritance of spatial positioning of peripheral heterochromatin through mitosis. eLife 8: e49278.

Politz, J. C. R., Scalzo, D. and Groudine, M. 2013. Something silent this way forms: The functional organization of the repressive nuclear compartment. Annu. Rev. Cell Dev. Biol. 29: 241-270.

Ruault, M., Dubarry, M. and Taddei, A. 2008. Re-positioning genes in the nuclear envelope in mammalian cells: Impact on transcription. Trends Genet. 24: 574-581.

Schreiber, G., Bogliolo, A. R. and Pinto, A. C. 1972. Cytogenetics of Triatominae: Karyotype, DNA content, nuclear size and heteropyknosis of autosomes. Brazil. J. Biol. 32: 255-263. 
Silveira, A. 2000. Profilaxia. In: Brener, Z., Andrade, Z. A. and Barral-Neto, M. (eds.). Trypanosoma cruzi e Doença de Chagas. Guanabara Koogan, Rio de Janeiro. pp. 75-86.

Solari, J. 1979. Autosomal synaptonemal complexes and sex chromosomes without axes in Triatoma infestans (Reduviidae: Hemiptera). Chromosoma 72: 225-240.

Towbin, B. D., Gonzales-Sandoval, A. and Gasser, S. M. 2013. Mechanisms of heterochromatin subnuclear localization. Trends Biochem. Sci. 38: 356-363.

Towbin, B. D., Meister, P. and Gasser, S. M. 2009. The nuclear envelope-A scaffold for silencing? Curr. Opin. Genet. Dev. 19: $180-186$.

Ueshima, N. 1966. Cytotaxonomy of the Triatominae (Reduviidae: Hemiptera). Chromosoma 18: 97-122.

Wasserlauf, I. E., Usov, K. E., Sibataev, A. K. and Stegniy, V. N. 2020.
Dynamics of the spatial orientation of the pericentromeric heterochromatin regions in the polytene chromosomes of ovarian nurse cells in the Drosophila melanogaster (Diptera: Drosophilidae) oogenesis. Nucleus 63: 7-15.

Wigglesworth, V. B. 1984. Insect Physiology, 8th Edn. Chapman and Hall, London.

Wijchers, P. J., Geeven, G., Eyres, M., Bergsma, A. J., Janssen, M., Verstegen, M., Zhu, Y., Schell, Y., Vermeulen, C., De Wit, E. and De Laat, W. 2015. Characterization and dynamics of pericentromere-associated domains in mice. Genome Res. 25: 958-969.

Yokochi, T., Poduch, K., Ryba, T., Lu, J., Hiratani, I., Tachibana, M., Shinkai, Y. and Gilbert, D. M. 2009. G9a selectively represses a class of late-replicating genes at the nuclear periphery. Proc. Natl. Acad. Sci. U.S.A. 106: 19363-19368. 